\title{
Mortality and economic burden of Krasnoyarsk region, Russia, caused by regular tobacco usage
}

\author{
This article was published in the following Dove Press journal: \\ International Journal of COPD \\ 22 February 2016 \\ Number of times this article has been viewed
}

\author{
Ivan P Artyukhov' \\ Irina L Arshukova ${ }^{2}$ \\ Elena A Dobretsova ${ }^{2}$ \\ Andrey V Shulmin ${ }^{2}$ \\ 'Department of Health Care \\ Management, ${ }^{2}$ Department of Public \\ Health and Health Care, Krasnoyarsk \\ State Medical University, Krasnoyarsk, \\ Russia
}

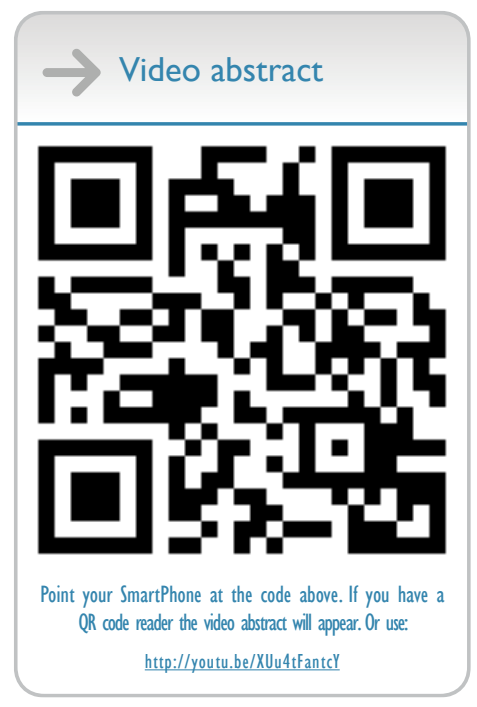

Correspondence: Irina L Arshukova Department of Public Health and Health Care, Krasnoyarsk State Medical University, Partizan Zheleznyak Street I, Krasnoyarsk 660022, Russia

Tel +79039200082

Email iarshukova@gmail.com
Background: This study assesses mortality and economic burden due to the regular tobacco usage among the population of the Krasnoyarsk region of the Russian Federation. This territory was chosen for the analysis because of two factors: high smoking prevalence in the Krasnoyarsk region ( $46 \%$ among the adult population) and premature mortality of the working-age population, which leads to a significant burden to the federal budget of the Russian Federation.

Data sources: In our work, three main causes of smoking-related deaths were considered: cardiovascular disease, lung cancer, and COPD. The working-age population was investigated (20-72 years old). The databases of mortality and population size of the territorial body of state statistics of the Krasnoyarsk region (data for 2013) were used as the information sources.

Methods: Joint application of population-attributable risk and disability-adjusted life years method allowed us to estimate medico-demographic and economic burden due to the tobaccoattributable premature mortality in the investigated population.

Results: We found that tobacco use-related economic burden is at least equal to $2 \%$ of the gross regional product of the Krasnoyarsk region in 2013.

Conclusion: An assessment of economic tobacco use-related burden is important for determining the volume of necessary funding for development of smoking prevention programs, proper estimation of tobacco companies' taxation, and other measures for controlling tobacco use. Smoking cessation is a priority for prevention of the tobacco-related diseases and reduction of their burden on local economy.

Keywords: lung cancer, COPD, cardiovascular disease, disability-adjusted life years, population-attributable risk, smoking-related mortality

\section{Introduction}

Tobacco smoking is a medical, social, and economic problem worldwide. Cigarette usage leads to development of many diseases, loss of health, and premature mortality. ${ }^{1-4}$ Regular tobacco smoking is responsible for approximately five million deaths in the world each year. According to studies done in Russia, smoking reduces life expectancy by $10-12$ years. ${ }^{5,6}$

According to the World Health Organization (WHO), there are over one billion smokers worldwide, and 44 million in Russia alone.?

Regular tobacco use enhances risks of many diseases such as malignant neoplasms, cardiovascular diseases (CVDs), respiratory diseases, tuberculosis, stroke, diabetes, and gastrointestinal diseases. The three leading causes of smoking-related deaths are lung cancer, ischemic heart disease, and COPD. ${ }^{1,5,8-14}$

Tobacco kills people of working age - the most skilled workers. Therefore, regular tobacco use leads to additional economic burden. ${ }^{8-10}$ Economic costs associated with cigarette smoking, calculated in several different ways, were obtained at a rate 
of $1 \%-3 \%$ of the gross domestic product of the Russian Federation. ${ }^{5,15,16}$

The present study focuses on assessing the Krasnoyarsk region budget costs caused by tobacco smoking-related premature mortality in the working population. This territory was chosen for specific reasons. Krasnoyarsk region is one of the major districts of the Russian Federation with a population of approximately three million people covering the territory, equal to $\sim 14 \%$ of the entire country. Krasnoyarsk region is one of the ten regions, responsible for $>50 \%$ of the gross domestic product of the Russian Federation and the federal budget. It is the absolute leader among other regions of the country in the development of industrial products per capita. The population of the region heavily contributes to the industrial work force (such as in the chemical and metallurgical industries). Thus, premature mortality in this population leads to a significant financial burden to the federal budget of the Russian Federation. Therefore, health preservation is not only social but also an important economic problem.

According to the Global Adult Tobacco Survey 2009, $39.1 \%$ of the adult population of the Russian Federation are regular smokers: $60.2 \%$ men and $21.7 \%$ women. ${ }^{17}$ Notably, the prevalence of smoking in the Krasnoyarsk region is higher than the average rates of smoking in Russia: $\sim 46 \%$ of the adult population in the Krasnoyarsk region are active smokers, $65 \%$ men and $30 \%$ women. ${ }^{18}$

Therefore, the investigation and prevention of tobaccorelated mortality and economic costs of the Krasnoyarsk region are important for the Russian Federation.

\section{Methods}

In our work, the three main smoking-related causes of deaths were considered (International Classification of Diseases-10 codes): CVD (I20-I25), lung cancer (C34), and COPD (J44). The adult population over 20 years old was investigated.

\section{Data sources}

The databases of mortality and population size of the territorial body of state statistics of the Krasnoyarsk region (data for 2013) were used as data sources. These databases contain information about the number of deaths by sex, age, and nosology. The data were collected by the 5 -year age groups (20-24, 25-29, 30-34 years of age, etc).

We used the data of L Schwartz (personal communication, October 2013) for estimation of cause-specific mortality relative risks (RRs) for the different age groups (stratified mortality RRs). ${ }^{19}$ The difference in tobacco smoking prevalence in the USA and the Russian Federation was taken into account.

\section{Ethical approval}

As the databases used for this study are depersonalized and the data are not identifiable, patient consent was not required and ethical approval was not sought as per the Declaration of Helsinki.

\section{Statistical analysis}

Medical-demographic burden due to premature mortality in the investigated population caused by tobacco-related diseases was estimated using the disability-adjusted life years (DALY) method. ${ }^{20}$

The DALY index provides an assessment of health loss (in years). It measures the difference between the current situation and an ideal situation where everyone lives up to the age of standard life expectancy in perfect health. ${ }^{20}$

The DALY index consists of two components: years lived with a disability (YLD) and years lost due to premature mortality (YLL). ${ }^{20-24}$

$$
\mathrm{DALY}=\mathrm{YLL}+\mathrm{YLD}
$$

In Russia, there are some obstacles to calculating demographic health loss due to disability using the DALY method (YLD component). This method requires information about the disease prevalence, average disease duration, and cause-specific disability weight. The required information is absent in the databases of the Russian official statistics. ${ }^{25}$ With regard to this, we used the DALY method only on the premature mortality data to estimate medical and demographic health loss.

The estimation of life years lost due to premature mortality was made using the formula given by Prüss-Üstün et al. ${ }^{20}$ This formula has been programmed into calculation spreadsheet templates for DALY that are available at the WHO website. The age-weighting modulation constant $K=0$ was used for our calculations.

To estimate the smoking-attributable mortality, the following approach was used: to calculate the number of deaths directly caused by smoking, the total number of deaths was multiplied by the smoking population-attributable risk (PAR). PAR is a measure of the number of deaths caused exclusively by the presence of a specific risk factor in the population. Its value depends on the risk factor prevalence (fraction of smokers) and its influence strength (cause-specific mortality 
Table I Cause-specific stratified mortality population-attributable risks

\begin{tabular}{|c|c|c|c|c|c|c|c|c|c|c|}
\hline \multirow[t]{2}{*}{ Cause (ICD- I 0 code) } & \multicolumn{10}{|c|}{ Age group, years } \\
\hline & $35-39$ & $40-44$ & $45-49$ & $50-54$ & $55-59$ & $60-64$ & $65-69$ & 70-74 & 75-79 & $80-84$ \\
\hline \multicolumn{11}{|l|}{ Men } \\
\hline Cardiovascular diseases (I20-125) & 0.49 & 0.69 & 0.70 & 0.62 & 0.51 & 0.44 & 0.34 & 0.27 & 0.17 & 0.16 \\
\hline Lung cancer (C34) & 0.10 & 0.64 & 0.77 & 0.92 & 0.96 & 0.95 & 0.94 & 0.94 & 0.92 & 0.88 \\
\hline COPD (J44) & 0.80 & 0.80 & 0.80 & 0.80 & 0.84 & 0.88 & 0.91 & 0.84 & 0.89 & 0.85 \\
\hline \multicolumn{11}{|l|}{ Women } \\
\hline Cardiovascular diseases (I20-I25) & 0.13 & 0.25 & 0.63 & 0.54 & 0.41 & 0.29 & 0.27 & 0.20 & 0.14 & 0.03 \\
\hline Lung cancer (C34) & 0.19 & 0.75 & 0.85 & 0.73 & 0.81 & 0.78 & 0.81 & 0.71 & 0.75 & 0.62 \\
\hline COPD (J44) & 0.76 & 0.76 & 0.76 & 0.76 & 0.69 & 0.73 & 0.79 & 0.75 & 0.74 & 0.76 \\
\hline
\end{tabular}

Abbreviation: ICD, International Classification of Diseases.

RR) and may be estimated using the standard attributable risk formula ${ }^{26}$ :

$$
\mathrm{PAR}=\frac{p_{\mathrm{s}} \cdot(\mathrm{RR}-1)}{1+p_{\mathrm{s}} \cdot(\mathrm{RR}-1)}=\frac{p_{\mathrm{n}}+p_{\mathrm{s}} \cdot(\mathrm{RR}-1)}{p_{\mathrm{n}}+p_{\mathrm{s}} \cdot \mathrm{RR}}
$$

where $p_{\mathrm{n}}$ is the fraction of nonsmokers, $p_{\mathrm{s}}$ is the fraction of current smokers, and RR is the relative risk of mortality for smokers compared to nonsmokers.

We estimated the years of potential life lost related to tobacco smoking by multiplying years lost due to premature mortality (YLL) by the appropriate PAR for each age group, nosology, and sex.

\section{Results}

Table 1 shows cause-specific PARs by age group and sex obtained using the standard attributable risk formula, stratified mortality RR data (the data of L Schwartz), ${ }^{19}$ and smoking prevalence data for the Russian Federation. The stratified mortality RR data are available only for the 35- to 84-year age group. Tobacco smoking consequences for health have a cumulative effect. To prevent overestimation of health loss, we set the PAR to zero for the 20- to 24-year age group, for the age group 25-29 - one-third of the risk value of the group 35-39, and for the age group 30-34 - two-thirds of 35-39 group risk value.

Table 2 shows the results from the main analysis of the tobacco-related cause-specific mortality, years of potential life lost, and economic burden by nosology and sex for the adult population under the age of 72. According to the "Methodology of economic cost of population mortality, morbidity and disability calculations" confirmed in 2012 by the Order No 323n of the Ministry of Public Health of the Russian Federation, 72 years is an age of expiry of the economic human activity. So, in our assessments, we assume that the working-age population is the population aged between 20 and 72 years.
Smoking-related mortality was obtained as the total number of deaths in a particular age group and nosology multiplied by the appropriate PAR. Smoking-related medical-demographic index DALY was estimated using the population size and smoking-related mortality data. Taking into account that the DALY unit represents lost years of healthy life, smoking-related economic burden is a multiplication of smoking-related DALY by gross regional product (GRP) per capita. GRP of the Krasnoyarsk region in 2013 amounts to $1,188.78$ billion rubles according to the territorial body of state statistics of the Krasnoyarsk region. It is equal to 419.5 thousand rubles per capita.

The value of the regional budget burden due to the smoking-related premature mortality in the population in 2013 is 22.12 billion rubles. According to the Central Bank of the Russian Federation, $1 €=42.60$ rubles and 1 US $\$=32.62$ rubles (the data on July 16, 2013). Thus, the total budget loss

Table 2 Tobacco-related cause-specific mortality, years of potential life lost, and economic burden by nosology and sex for the adult population aged $20-72$ years

\begin{tabular}{|c|c|c|c|c|c|}
\hline \multirow{2}{*}{$\begin{array}{l}\text { Cause } \\
\text { (ICD-10 code) }\end{array}$} & \multirow[t]{2}{*}{ SAM } & \multirow{2}{*}{$\begin{array}{l}\text { SA } \\
\text { DALY }\end{array}$} & \multicolumn{3}{|c|}{ SA economic burden } \\
\hline & & & $\begin{array}{l}\text { Rubles } \\
\text { (million) }\end{array}$ & $\begin{array}{l}\text { Euros } \\
\text { (million) }\end{array}$ & $\begin{array}{l}\text { USD } \\
\text { (million) }\end{array}$ \\
\hline Total & 3,959 & 52,730 & 22,119 & 519.3 & 678.1 \\
\hline \multicolumn{6}{|l|}{ Men } \\
\hline $\begin{array}{l}\text { Cardiovascular } \\
\text { diseases }(120-125)\end{array}$ & 2,217 & 29,519 & 12,383 & 290.7 & 379.6 \\
\hline Lung cancer (C34) & 678 & 7,891 & 3,310 & 77.7 & 101.5 \\
\hline COPD (J44) & 119 & 1,338 & 561 & 13.2 & 17.2 \\
\hline Total & 3,014 & 38,748 & 16,254 & 381.6 & 498.3 \\
\hline \multicolumn{6}{|l|}{ Women } \\
\hline $\begin{array}{l}\text { Cardiovascular } \\
\text { diseases (120-125) }\end{array}$ & 801 & 11,944 & 5,010 & 117.6 & 153.6 \\
\hline Lung cancer (C34) & 108 & $\mathrm{I}, 562$ & 655 & 15.4 & 20.1 \\
\hline COPD (J44) & 36 & 476 & 200 & 4.7 & 6.1 \\
\hline Total & 945 & 13,982 & 5,865 & 137.7 & 179.8 \\
\hline
\end{tabular}

Abbreviations: SAM, smoking-attributable mortality; SA, smoking-attributable DALY, disability-adjusted life years; ICD, International Classification of Diseases. 
corresponds to 519.3 million euros or 678.1 million dollars. The amount of the damage has resulted in a loss of $2 \%$ of the GRP of the Krasnoyarsk region in 2013. These costs could be avoided if the people of the region did not smoke.

\section{Conclusion}

Our study investigates mortality and economic burden assessments due to the regular tobacco usage in the population of the Krasnoyarsk region. This territory was chosen for the analysis because of the two factors: higher smoking prevalence compared to the average rates of smoking in Russia and tobacco use-related high premature mortality rates in the population. These factors collectively lead to a significant financial burden to the federal budget of the Russian Federation, as premature mortality in the working-age population results in significant GRP loss. We found that tobacco-related economic burden is at least equal to $2 \%$ of the GRP of the Krasnoyarsk region in 2013. These estimates, however, reflect only some of the economic costs of tobacco smoking.

We analyzed three main causes of smoking-related deaths: CVD, COPD, and lung cancer. It should be noted that regular tobacco smoking enhances risk for many other diseases. Therefore, additional consideration of these diseases will raise the value of the economic burden. Here, we estimated economic burden based only on assessment of tobacco use-related deaths, as smoking is associated with a high morbidity. In addition to the loss of GRP, smokingrelated economic burden includes hospitalization expenses and disability payments. We did not consider the impact of secondhand smoke in our analysis.

WHO Framework Convention on Tobacco Control summarizes the world effort to effectively control tobacco use. ${ }^{27}$ Presently, there is a worldwide emphasis on reducing the prevalence and intensity of tobacco smoking. ${ }^{28,29}$

The Federal Law No 15-FZ, "On the protection of public health from exposure to environmental tobacco smoke and effects of tobacco exposure" was adopted by the Russian Federation on February 23, 2013. One of the expected results is a reduction of smoking prevalence in the country.

Reduction in tobacco usage will lead to an increase in life expectancy in the population of working age people, reduce medical fees and disability payments, and decrease tax losses from regional businesses. Collectively, these will significantly reduce the economic burden to the federal budget of the Russian Federation. Therefore, development of programs and incentives for smoking cessation is a priority for prevention of the tobacco use-related diseases and reduction of their impact on the economy of the Russian Federation.

\section{Acknowledgments}

The authors wish to thank Lisa Schwartz for kind communication and data of stratified mortality RR related to smoking dependent on sex, age group, and nosology. The authors also sincerely appreciate Lena Khibnik for significant English grammar review.

\section{Disclosure}

The authors report no conflicts of interest in this work.

\section{References}

1. CDC. Smoking-attributable mortality, years of potential life lost, and productivity losses - United States, 2000-2004. MMWR Morb Mortal Wkly Rep. 2008;57(45):1226-1228.

2. Abdullah ASM, Husten CG. Promotion of smoking cessation in developing countries: a framework for urgent public health interventions. Thorax. 2004;59:623-630.

3. Ezzati M, Lopez AD. Estimates of global mortality attributable to smoking in 2000. Lancet. 2003;362(9387):847-852.

4. Peto R, Boreham J, Lopez AD, Thun M, Heath C. Mortality from tobacco in developed countries: indirect estimation from national vital statistics. Lancet. 1992;339(8804):1268-1278.

5. Report of Civic Chamber. Tabachnaja jepidemija v Rossii: prichiny, posledstvija, puti preodolenija [The Tobacco Epidemic in Russia: Causes, Consequences and Ways to Overcome]. Moscow; 2009. Russian.

6. Sharaykina EN, Demko IV, Petrova MM. Vozrastnye aspekty tabakokurenija sredi muzhchin i zhenshhin Krasnojarskogo kraja [Age aspects of smoking among men and women of Krasnoyarsk region]. Siberian Med Rev. 2011;4:56-59. Russian.

7. World Health Organization. WHO report on the global tobacco epidemic, 2008 : The MPOWER package. Geneva: World Health Organization; 2008. Available from: http://www.who.int/tobacco/mpower/ mpower_report_full_2008.pdf. Accessed January 25, 2016.

8. Barendregt JJ, Bonneux L, van der Maas PJ. The health care costs of smoking. N Engl J Med. 1997;337:1052-1057.

9. Nonnemaker J, Rostron B, Hall P, MacMonegle A, Apelberg B. Mortality and economic costs from regular cigar use in the United States, 2010. Am J Public Health. 2014;104(9):e86-e91.

10. Ruff LK, Volmer T, Nowak D, Meyer A. The economic impact of smoking in Germany. Eur Respir J. 2000;16:385-390.

11. Mackay J. The global epidemiology of tobacco and related chronic diseases. Public Health. 2012;126(3):199-201.

12. Ezzati M, Henley SJ, Lopez AD, Thun MJ. Role of smoking in global and regional cancer epidemiology: current patterns and data needs. Int $J$ Cancer. 2005;116(6):963-971.

13. Oster G, Colditz GA, Kelly NL. The economic costs of smoking and benefits of quitting for individual smokers. Prev Med. 1984;13(4): 377-389.

14. Katsiki N, Papadopoulou SK, Fachantidou AI, Mikhailidis DP. Smoking and vascular risk: are all forms of smoking harmful to all types of vascular disease? Public Health. 2013;127(5):435-441.

15. Zasimova LS. Kurenie na rabote i oplata truda [Smoking at the work place and labor remuneration]. Motiv Labor Remun. 2010;4:242-249. Russian.

16. Ross HZ, Shariff S, Gilmore A. Economics of Tobacco Taxation in Russia. Paris: International Union Against Tuberculosis and Lung Disease; 2008.

17. Global Adult Tobacco Survey (GATS). Russian Federation Country Report; 2009.

18. Aristov AI, Demko IV, Kononova LI. Okazanie medicinskoj pomoshhi $\mathrm{v}$ otkaze ot kurenija tabaka [Medical Assistance in Tobacco Smoking Cessation]. Krasnoyarsk: KrasGMU; 2011. Russian. 
19. Woloshin S, Schwartz LM, Welch HG. The risk of death by age, sex, and smoking status in the United States: putting health risks in context. J Natl Cancer Inst. 2008;100(12):845-853.

20. Prüss-Üstün A, Mathers C, Corvalan C, Woodward A. Introduction and Methods: Assessing the Environmental Burden of Disease at National and Local Levels. Geneva: World Health Organization; 2003.

21. Murray CJ, Acharya AK. Understanding DALYs. J Health Econ. 1997; $16: 703-730$.

22. Murray CJL, Lopez AD. The Global Burden of Disease. A Comprehensive Assessment of Mortality and Disability from Diseases, Injuries and Risk Factors in 1990 and Projected to 2020. Cambridge, MA: Harvard School of Public Health on Behalf of the World Health Organization and the World Bank; 1996.

23. Gold MR, Siegel JE, Weinstein MC, Russell LB. Cost-Effectiveness in Health and Medicine. New York: Oxford University Press; 1996.

24. National Research Council. New Vaccine Development: Establishing Priorities: Volume II, Diseases of Importance in Developing Countries. Washington, DC: The National Academies Press; 1986.
25. Ivanova AE, Mikhailov AYu. Metodologija ocenki jekonomicheskih poter' ot nezdorov'ja [Methodology for estimating the economic costs of ill health]. Manager Health Care. 2012;2:33-37. Russian.

26. Levin ML. The occurrence of lung cancer in man. Acta Unio Int Contra Cancrum. 1953;9(3):531-541.

27. World Health Organization. Framework Convention on Tobacco Control, Preamble. Geneva: WHO Document Production Services; 2005.

28. Raw M, Regan S, Rigotti NA, McNeill A. A survey of tobacco dependence treatment guidelines in 31 countries. Addiction. 2009;104(7): 1243-1250.

29. Raw M, Anderson P, Batra A, et al. WHO Europe evidence based recommendations on the treatment of tobacco dependence. Tob Control. 2002;11:44-46.

\section{Publish your work in this journal}

The International Journal of COPD is an international, peer-reviewed journal of therapeutics and pharmacology focusing on concise rapid reporting of clinical studies and reviews in COPD. Special focus is given to the pathophysiological processes underlying the disease, intervention programs, patient focused education, and self management protocols.

\section{Dovepress}

This journal is indexed on PubMed Central, MedLine and CAS. The manuscript management system is completely online and includes a very quick and fair peer-review system, which is all easy to use. Visit http://www.dovepress.com/testimonials.php to read real quotes from published authors.

Submit your manuscript here: http://www.dovepress.com/international-journal-of-chronic-obstructive-pulmonary-disease-journal 